\title{
PATTERN OF SUICIDAL DEATHS- A REVIEW OF AUTOPSY CASES IN 2015 AND 2016
}

\author{
Balaram N. A1, Mahaju C. Fathima², Antony L. Arakkal ${ }^{3}$, Balavenkataperumal ${ }^{4}$ \\ 1 Professor and HOD, Department of Forensic Medicine, Government Medical College, Thrissur. \\ 2Junior Resident, Department of Forensic Medicine, Government Medical College, Thrissur. \\ 3 Junior Resident, Department of Forensic Medicine, Government Medical College, Thrissur. \\ ${ }^{4}$ Senior Resident, Department of Forensic Medicine, Government Medical College, Thrissur.
}

\begin{abstract}
BACKGROUND

Suicide is high in societies that are socially isolated, mobile and disorganised. Differences exist in countries in the most common means of suicide depending on the availability of various methods. Different suicide risk factors are present in different age groups. Thus, suicide which is very much a by-product of the advancements of society needs a careful and refined approach, so as to study the factors related to it, the causes and if possible to find ways to prevent such a tragedy.

The present study was designed to study the pattern of suicidal deaths in the years 2015 and 2016.
\end{abstract}

\section{MATERIALS AND METHODS}

The post-mortem registers of Government Medical College, Thrissur during the study period, the post-mortem detailed notes and Kerala Police Form 102 and laboratory investigations of the cases whose cause of death was suicide during the study period.

\section{RESULTS}

Out of 3074 autopsies done, 994 cases were suicidal deaths. Hanging was the most common method of suicide (49.8\%). Suicidal deaths were found to be more among males (59.5\%), married (60.2\%) and in the age group $31-50(34.4 \%)$.

\section{CONCLUSION}

In our study, most of the victims were married males with mental instability belonging to age group 31 - 50 years and majority died due to hanging.

\section{KEYWORDS}

Suicide, Hanging, Poisoning, Drowning, Burns.

HOW TO CITE THIS ARTICLE: Balaram NA, Fathima MC, Arakkal AL, et al. Pattern of suicidal deaths- a review of autopsy cases in 2015 and 2016. J. Evolution Med. Dent. Sci. 2017;6(59):4372-4374, DOI: 10.14260/Jemds/2017/945

\section{BACKGROUND}

Suicide (Latin suicidium, from sui caedere, "to kill oneself") is the act of intentionally causing one's own death. According to Durham, the French biologist, suicide is death resulting directly or indirectly from a positive or negative act of the victim himself, which he knows will produce this result. [1]

Suicide is high in societies that are socially isolated, mobile and disorganised. It is lower in countries or subcultures, whose religious or cultural morals proscribe suicide. Different suicide risk factors are present in different age groups. The teenager cannot compete, in the young and middle-aged adult there is a lack of accomplishment of life goals along with failure in social relationships, while in the elderly there is loss of friends and loved ones, health and financial problems and idea of death.[2]

Differences exist in countries in the most common means of suicide depending on the availability of various methods. According to National Crime Record Bureau the common means adopted for suicide in India are poisoning, hanging, drowning, jumping from height, jumping against moving train, firearm and burns, etc.

Financial or Other, Competing Interest: None.

Submission 05-07-2017, Peer Review 17-07-2017,

Acceptance 20-07-2017, Published 24-07-2017.

Corresponding Author:

Dr. Mahaju C. Fathima

Chekidappurath House,

Kattungal, Irumbuzhi P. O.,

Malappuram-676509, Kerala.

E-mail: mahajucfathima1986@gmail.com

DOI: $10.14260 /$ jemds $/ 2017 / 945$
In England and Wales men use hanging, poisoning by gas or vehicle exhaust and women are more likely to take an overdose, but in USA the most common method of suicide is firearm, ${ }^{[3]}$ while in Singapore jumping from a height is the commonest mode.[4]

Thus, suicide which is very much a by-product of the advancements of society needs a careful and refined approach, so as to study the factors related to it, the causes and if possible to find ways to prevent such a tragedy. The objective of this study is to characterise the pattern of suicide cases reported to Govt. Medical College, Thrissur, over the years 2015 and 2016 and to describe the pattern of suicide in these cases with respect to socio-demographic profile.

\section{MATERIALS AND METHODS}

A retrospective descriptive study was conducted at Department of Forensic Medicine, Government Medical College, Thrissur in two years (2015 and 2016). The cases of suicides were identified and their detailed post-mortem notes, Kerala police form 102 and laboratory investigation reports were examined. From these records, data regarding age, gender, religion, marital status, risk factors, methods of suicide and special cases (like dowry deaths, suicidal pacts, etc.) were collected and entered in MS Excel software and analysed using SPSS software.

\section{RESULTS}

Out of the total 3074 autopsies done (1528 in the year 2015 and 1546 in 2016), there were 520 cases of suicidal deaths in the year 2015 and 474 cases in 2016. Study based on age- 
wise distribution of cases showed maximum number of cases, $342(34.4 \%)$ in the age group 31 - 50 followed by the age group 11 - 30 (28.9\%). Gender based study showed that maximum number of cases were of males 591 (59.5\%). Suicidal deaths were more common in married, i. e. 598 cases (60.2\%) compared to unmarried 103 cases (10.4\%). Study based on religion was of no significance since majority of population in Kerala comprised Hindus. Study also showed that the most common method of suicide was hanging, 495 cases $(49.8 \%)$ followed by poisoning 246 cases $(24.7 \%)$. The suicidal deaths were associated with presence of incurable diseases in 146 cases (14.7\%) and family problems in 96 cases (9.7\%). Suicidal pact was present in only few cases 17 (1.7\%). Maximum number of deaths, 365 cases $(36.7 \%)$ occurred within 12 hours of suicidal attempt.

\begin{tabular}{|c|c|c|}
\hline Age Group & Frequency & Percent \\
\hline $11-30$ & 287 & 28.9 \\
\hline $31-50$ & 342 & 34.4 \\
\hline $51-70$ & 280 & 28.2 \\
\hline $71-90$ & 83 & 9.3 \\
\hline Above 90 & 2 & 0.2 \\
\hline Total & $\mathbf{9 9 4}$ & $\mathbf{1 0 0 . 0}$ \\
\hline \multicolumn{2}{|c|}{ Table 1. Distribution based on Age } \\
\hline
\end{tabular}

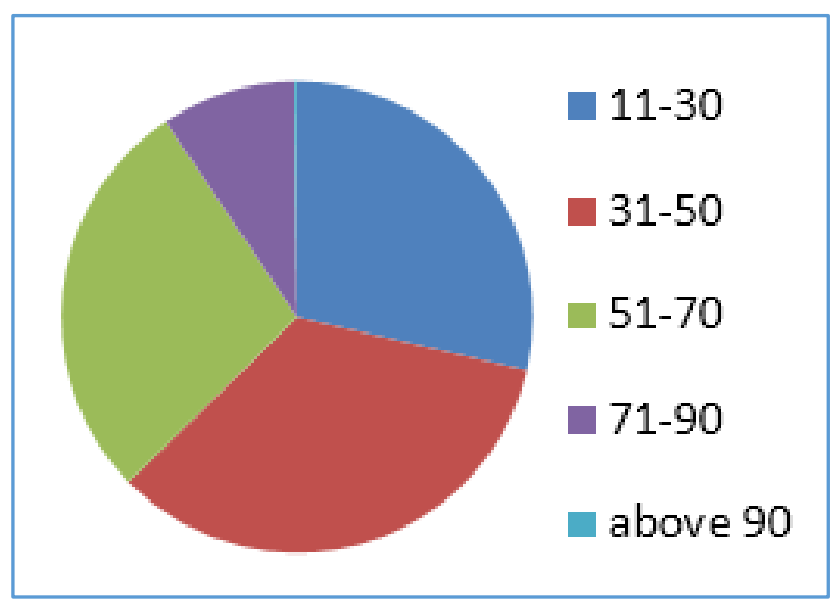

Distribution based on Age

\begin{tabular}{|c|c|c|}
\hline Gender & Frequency & Percent \\
\hline Female & 403 & 40.5 \\
\hline Male & 591 & 59.5 \\
\hline Total & $\mathbf{9 9 4}$ & $\mathbf{1 0 0 . 0}$ \\
\hline \multicolumn{2}{|c|}{ Table 2. Distribution based on Gender } \\
\hline
\end{tabular}

\begin{tabular}{|c|c|c|}
\hline Marital Status & Frequency & Percent \\
\hline Unmarried & 103 & 10.4 \\
\hline Married & 598 & 60.2 \\
\hline Not Known & 293 & 29.5 \\
\hline Total & $\mathbf{9 9 4}$ & $\mathbf{1 0 0 . 0}$ \\
\hline \multicolumn{3}{|c|}{ Table 3. Marital Status } \\
\hline
\end{tabular}

\begin{tabular}{|c|c|c|}
\hline Religion & Frequency & Percent \\
\hline Christian & 94 & 9.5 \\
\hline Hindu & 823 & 82.8 \\
\hline Muslim & 77 & 7.7 \\
\hline Total & $\mathbf{9 9 4}$ & $\mathbf{1 0 0 . 0}$ \\
\hline \multicolumn{2}{|r|}{ Table 4. Religion Wise Distribution } \\
\hline
\end{tabular}

\begin{tabular}{|c|c|c|}
\hline Cause & Frequency & Percent \\
\hline Hanging & 495 & 49.8 \\
\hline Poisoning & 246 & 24.7 \\
\hline Burns & 190 & 19.1 \\
\hline Drowning & 48 & 4.8 \\
\hline Railway & 8 & 0.8 \\
\hline Firearm injury & 3 & 0.3 \\
\hline Incised wound wrist & 3 & 0.3 \\
\hline Electric shock & 1 & 0.1 \\
\hline Total & $\mathbf{9 9 4}$ & $\mathbf{1 0 0 . 0}$ \\
\hline \multicolumn{2}{|r}{ Table 5. Cause of Death } \\
\hline
\end{tabular}

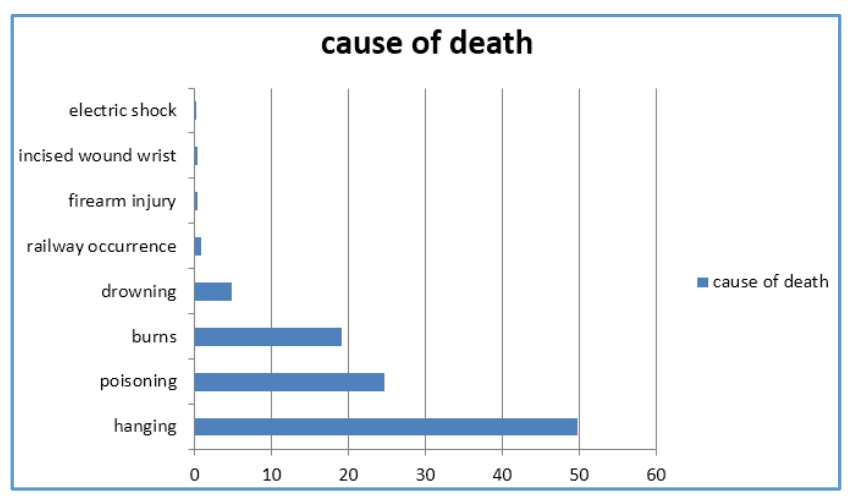

\begin{tabular}{|c|c|c|}
\hline Suicidal Pact & Frequency & Percent \\
\hline No & 970 & 97.6 \\
\hline Yes & 17 & 1.7 \\
\hline Not Known & 7 & 0.7 \\
\hline Total & $\mathbf{9 9 4}$ & $\mathbf{1 0 0 . 0}$ \\
\hline \multicolumn{3}{|c|}{ Table 6. Suicidal Pact } \\
\hline
\end{tabular}

\begin{tabular}{|c|c|c|}
\hline Survival Time & Frequency & Percent \\
\hline Within 12 hrs. & 365 & 36.7 \\
\hline 12 hrs. to 24 hrs. & 90 & 9.1 \\
\hline 1-5 days & 149 & 15.0 \\
\hline 6-10 days & 47 & 4.7 \\
\hline 11-15 days & 6 & 0.6 \\
\hline 16-20 days & 5 & 0.5 \\
\hline $21-25$ days & 5 & 0.5 \\
\hline 26-30 days & 1 & 0.1 \\
\hline More than one month & 1 & 0.1 \\
\hline Not known & 325 & 32.7 \\
\hline Total & 994 & 100.0 \\
\hline \multicolumn{3}{|c|}{ Table 7. Survival Time } \\
\hline
\end{tabular}

\section{DISCUSSION}

In this study hanging was found to be the most commonly adopted method for suicide (49.8\%) followed by poisoning (24.7\%), burns (19.1\%), drowning (4.8\%), etc. According to Behera A and Colleagues, Vikram Patel et al[1,5] the most common method employed to die were poisoning, hanging, burns and drowning in the decreasing order. According to the studies of Meera T et al[6] Sharija S et al[7] Vijaykumari ${ }^{[8]}$ hanging and self-immolation were the most common methods employed for suicide.

As per this study, the major factor leading to suicide was mental instability which was present in almost all cases followed by presence of incurable diseases in 146 cases $(14.7 \%)$ and family problems in $96(9.7 \%)$ cases. According to WHO, poverty was the major factor for suicide followed by 
stress, mental illness, unemployment and substance abuse. ${ }^{[9]}$ According to the study of Behera A et al, majority of the victims belonged to lower socioeconomic class.[1] Economic causes, poverty and familial conflicts are the leading causes in the studies of Behera A et al,[1] Meera $\mathrm{T}$ et al,[6] Sharija $\mathrm{S}$ et al[7] and Vijaykumari N. ${ }^{[8]}$ This is also similar to the National Crime Research Bureau[10] data. This finding is relevant as economic instability and indebtedness leads to the person being termed an outcast in the society, which leads to suicide. Also Meera $\mathrm{T}$ et al[6] mentions illness as another important factor.

In this study, maximum number of cases were males, 591 cases (59.5\%). According to the study conducted by Meera T et $\mathrm{al}^{[6]}$ highest number of cases were observed in males as the financial responsibility is heaped solely on the males in our society.

In this study, maximum number of cases were noted in the age group $31-50,342$ cases (34.4\%) followed by the age group $11-30,287$ cases (28.9\%). According to the studies by Behera A et al[1] Meera $T$ et al[6] Sharija $S$ et al[7] and Vijaykumari $\mathrm{N}^{[8]}$ most of the victims belong to the age group between 21 - 30 and 31 - 40 years.

This study also showed that suicidal deaths were more common in married i.e. 598 cases $(60.2 \%)$ compared to unmarried 103 cases (10.4\%). Studies by Behera A et al,[1] Meera $\mathrm{T}$ et al[6] Sharija $\mathrm{S}$ et al[7] and Vijaykumari $\mathrm{N}^{[8]}$ shows that majority of cases were married. This study also showed that suicidal deaths were more common in married, i.e. 598 cases $(60.2 \%)$ compared to unmarried 103 cases (10.4\%).

\section{CONCLUSION}

In our study, most of the victims were married males with mental instability belonging to age group 31 - 50 years and majority died due to hanging. The result of this study indicates that by not only a strong legal support network but also opportunities for economic independency, essential education and awareness, alternative accommodation and a change in attitude and mindset of society, judiciary, legislature, executive and the most importantly person himself can lower or prevent the suicidal deaths.

\section{REFERENCES}

[1] Behera A, Balabantry JK, Nayak SR. Review of suicidal cases. A retrospective study. J Indian Acad Forensic Med 2005;27(2):100-2.

[2] Nwosu SO, Odesanmi WO. Pattern of suicides in lle-lfe, Nigeria. West African Journal of Medicine 2001;203):259-62.

[3] Di Maio VJ. Gunshot wounds practical aspects of firearms, ballistics and forensic techniques. New York: CRC Press 1993:293-4.

[4] Peng KL, Choo AS. Suicide and parasuicide in Singapore (1986). Medicine Science Law 1990;30(3): 225-33.

[5] Vijaykumar L. Psycho social risk factors for suicide in India. In: Vijaykumar L. edr. Suicide prevention meeting the challenges together. Hyderabad, India: Orient Longman 2003;149-62.

[6] Meera T, Singh MBK. Pattern of neck findings in suicidal hanging. A study in Manipur. J Indian Acad Forensic Med 2011;33(4):352-4.

[7] Patel V, Ramasundarahettige C, Vijayakumar L, et al. Suicide mortality in India: a nationally representative survey. The Lancet 2012:379(9834):2343-51.

[8] Sharija S, Sreekumari K, Geetha O. Epidemiological profile of suicide by hanging in southern parts of kerala: an autopsy based study. J Indian Acad Forensic Med 2011;33(3):237-40.

[9] Durkheim E. A study in sociology trans by Spolding JA \& Simpson G. with introduction by Simpson Glancole. Free Press 1917.

[10] National Crime Records Bureau. Unnatural deaths. India 2014. 